\title{
THE ECONOMIC COSTS AND CO-BENEFITS OF CARBON TAXATION: A GENERAL EQUILIBRIUM ASSESSMENT*
}

\author{
JARED WOOLLACOTT \\ RTI International, 3040 East Cornwallis Road \\ 12194, Research Triangle Park, NC, 27709-2194, USA \\ Jwoollacott@rti.org
}

Received 19 September 2017

Revised 28 December 2017

Accepted 3 January 2018

Published 20 March 2018

\begin{abstract}
I examine the general equilibrium costs of climate policies that levy taxes on carbon dioxide $\left(\mathrm{CO}_{2}\right)$ emissions in the United States and return the revenue in the form of lump-sum rebates and tax relief over the years 2020 to 2040 using the US regional version of the Applied Dynamic Analysis of the Global Economy (ADAGE-US) forward-looking dynamic Computable General Equilibrium (CGE) model. I approximate the value of co-benefits to these policies that arise from concomitant reductions in nongreenhouse gas (GHG) emissions using the CO-Benefits Risk Assessment model (COBRA). There is significant heterogeneity in costs and co-benefits from climate policies across space and income. Policy costs are generally less than $0.5 \%$ in equivalent variation terms (between a few tens of dollars and several hundred per household, depending on the income quintile), can be fully neutralized for the lowest- quintile households at a modest increase in overall policy cost, and tend to be lower for upper-quintile households in coastal regions. The policy co-benefit values range widely across regions, approximately $\$ 150-1250$ per household, exceeding the gross cost of the policy for many households, particularly those in the Midwest. Last, I identify a marginal welfare cost of $\$ 58 / \mathrm{tCO}_{2}$ and a marginal co-benefit of $\$ 31 / \mathrm{tCO}_{2}$ at a national level over all households, which implies a required climate benefit of $\$ 27 / \mathrm{tCO}_{2}$ or less to justify the level of abatement achieved by a $\$ 25 / \mathrm{tCO}_{2}$ tax growing at $5 \%$.
\end{abstract}

Keywords: Climate policy; general equilibrium; carbon tax; co-benefits.

JEL Codes: C68, Q43, Q48, Q52, Q54, Q58

\section{Introduction}

Calls for climate policy in the private sector and Congress have increasingly focused on taxing carbon over other alternatives, such as capping and trading it or mandating technology-specific emissions rates. One appeal of a tax is its potential to support other

\footnotetext{
*This article contains supplementary material available on the journal website. Supplementary material includes maps of the gross and net welfare impacts by quintile for the $\$ 25$ per ton, $5 \%$ increasing tax with lump-sum recycling.

This is an Open Access article published by World Scientific Publishing Company. It is distributed under the terms of the Creative Commons Attribution 4.0 (CC-BY) License. Further distribution of this work is permitted, provided the original work is properly cited.
} 
fiscal objectives, such as broad-scale tax reform. Despite a narrowing focus on carbon taxes to the exclusion of such alternatives, carbon tax policy options abound and uncertainty lingers about the relative economic impacts of carbon tax options, such as the level, rate of increase, uses of funds raised, border adjustments, and others. The value of the tax and the use of the revenue it raises have significant influence on the level and distribution of economic costs that will be borne by households and firms. Results from ADAGE-US suggest that the level and distribution of the policy's cobenefits also vary with tax levels and show considerable spatial variation, but they are relatively insensitive to how the revenue is used. ${ }^{1}$ Using the ADAGE-US model, I show how different tax and "recycling" options outlined by the EMF32 study impact households across nine regions and five income quintiles through changes in income and expenditures. I use the COBRA screening model to approximate the level of cobenefit associated with each of the policies based on percent changes in regional fossil fuel consumption. Mapping the significant regional variation in policy co-benefits reveals that households in many areas are made better off by the policy without considering climate benefits. The marginal welfare and co-benefit of climate policy also shows considerable regional variation, with the implied climate benefits required to justify the policy being both negative and positive.

This research contributes a novel comparison of spatial and income-disaggregated costs and co-benefits of climate policy. While the national welfare impacts identified here are consistent with prior findings (Nemet et al., 2010), disaggregating policy outcomes reveals considerable heterogeneity in costs and co-benefits of carbon taxation that is relevant to optimal policy design. The higher spatial and economic resolution of policy costs and co-benefits contributed by this research can support the formation of carbon policies that mitigate undue impacts on particular groups. The efficiency analysis demonstrates how policy co-benefits can substantially reduce or even eliminate the net economic cost of climate policy even absent consideration of the policy's climate benefits.

\section{Background}

\subsection{Cost modeling}

The US-regional Applied Dynamic Analysis of the Global Economy (ADAGE-US) model is a perfect-foresight dynamic computable general equilibrium (CGE) model. ADAGE-US models 10 sectors in nine Census regions of the United States with nine household types defined by income. ${ }^{2}$ IMPLAN (2013) provides the benchmark data, which are revised and projected to the model horizon according to energy use data

\footnotetext{
${ }^{1}$ Co-benefits are any benefits arising from the policy that are not directly related to the target of the policy, climate change. For example, lower rates of illness from air pollutants that are lower as a result of the policy lowers. Total GHG emissions, and thereby climate benefits, are also relatively insensitive to how revenue is used.

${ }^{2}$ The 10 model sectors are agriculture, manufacturing, services, transportation, energy-intensive manufacturing, coal, crude oil, natural gas, refined oil, and electricity.
} 
from the Energy Information Administration's Annual Energy Outlook 2016 (AEO2016 no Clean Power Plan scenario). Income groups in ADAGE-US are those provided by IMPLAN (2013), which bases its classification on the Bureau of Labor Statistics' (BLS) Consumer Expenditure Survey (2016). These data also form the basis for differences in expenditure patterns by households. Quintile groups aggregate households defined on the IMPLAN/BLS income groupings. ${ }^{3}$ The model solves in five-year increments from 2015 through 2050. Terminal conditions return the model to a balanced growth path in the final periods by requiring that consumption and investment grow at the same rate.

Households own the economy's endowments of labor, capital, and natural resources, selling them in their respective markets to earn income. Households own endowments of both new and vintage capital. New capital is sold into a national market and then demanded by regional producers. Vintage capital is sector and region specific, depreciates over time, and is replaced by new capital supported by investment. For each period, households substitute between providing labor to their local market (i.e., there is no labor mobility across regions) or consuming leisure time. The combination of consumption and leisure produce welfare, which households can substitute across periods according to an elasticity of substitution of 0.5 . Households also receive transfer payments with fixed real value growing at the model balanced growth rate of $2.5 \%$. From their earnings in factor markets, households purchase transportation and consumption goods and services. Goods and services are supplied by intraregional, interregional, and international producers with differentiated substitution among these sources. Figure 1 diagrams the general structure of consumption and production in the ADAGE-US model. Production structures vary by sector. For example, fossil fuel industries (e.g., mining) and agriculture demand sector-specific resources that enter in the top nest of their production structures.

A government agent collects taxes, facilitates transfer payments, and funds public goods. The government agent's "welfare" is kept constant in all policy runs, with the marginal fiscal impact of the policy borne by households proportional to their capital endowment. Constant welfare for the government is particularly important in the revenue recycling scenarios, where carbon tax revenue is "recycled" back to households net of the policy's fiscal impact. In the policy scenarios considered here revenue is returned as labor or capital tax rebates, as a lump-sum payment, or some combination thereof.

The ADAGE-US model is designed to measure the economic costs of the policy and track the emissions reductions it affects, not the monetary value of emissions reductions. The model does not consider how the policy benefits might feed back to households and government to alter their behavior. Although by recycling the carbon tax revenue households have the opportunity to recoup their increased direct and

\footnotetext{
${ }^{3}$ Quintile 1 includes three IMPLAN groups with incomes less than $\$ 25,000$, quintile 2 includes two groups with incomes $\$ 25,000-50,000$, quintile 3 includes one group with incomes $\$ 50,000-75,000$, quintile four includes one group with incomes 75,000-100,000, and quintile 5 includes two groups with incomes $100,000+$.
} 


\section{J. Woollacott}

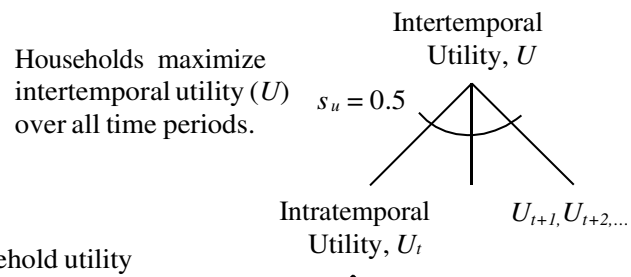

In time $t$, household utility

is a CES function of consumption and leisure.

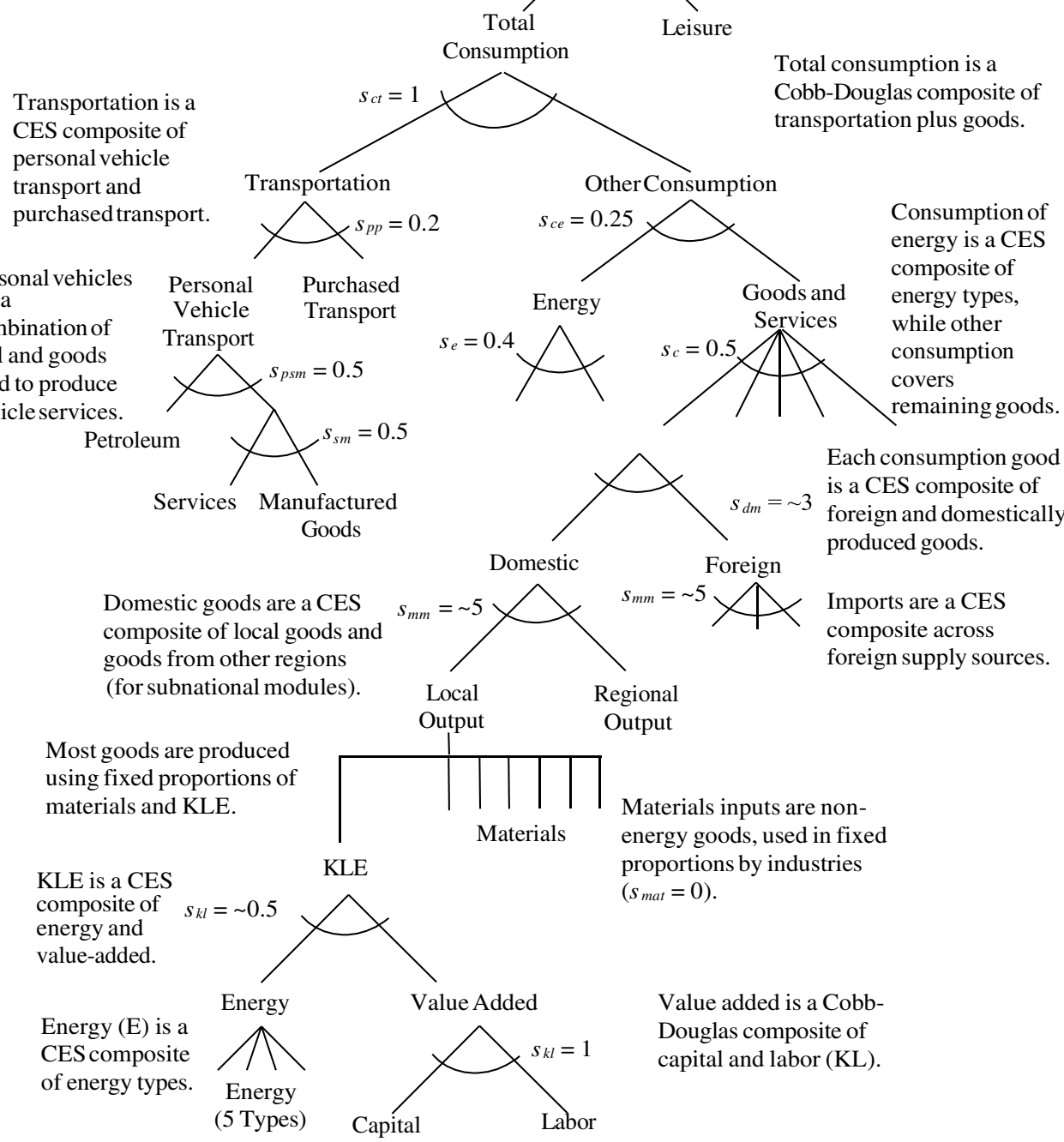

Figure 1. ADAGE model structure (Figs. 1-4 of Ross (2009)).

indirect energy costs, the tax induces economic inefficiencies that prevent transferring the full value of revenue collected.

The net effect of the tax on households will arise from a combination of changes in public and private income and expenditure. The complexity of interactions that give 
rise to these changes is ideally tracked from an economy-wide perspective, such as that offered by a general equilibrium model. Equivalent variation measures the net effect of these changes on households in reporting the change in households' economic wellbeing or utility relative to their current economic situation. It answers what variation in current income would be equivalent to the utility loss or gain experienced under the policy. By summarizing the net impact on a household's economic well-being relative to status quo economic conditions, equivalent variation is a helpful measure in evaluating whether new policies are worth implementing (Pizer et al., 2003).

The carbon tax will have a differential impact on the value of income sources and the costs of consumption and investment. Households that rely more heavily on sources of income with larger declines in value and consume and invest in goods and services with higher price increases will be made relatively worse off by the policy, all else equal. Similarly, households situated in regions whose economies are relatively more carbon intensive will face larger policy costs and welfare losses under the policy, all else equal. Household outcomes will therefore vary over income and geography. These variations can inform how we structure revenue recycling in an optimal carbon tax policy so that its economic impacts do not disproportionately impact certain groups. Policy makers' preferences on the distribution of impacts will no doubt vary, and economics cannot answer which distribution should be targeted, but the results here can help outline the economic consequences of the different options policy makers face.

\subsection{Benefits}

The ADAGE-US model provides a tractable mechanism for examining the economic costs households will face under different carbon policies. It does not offer any estimate of the economic benefit of a carbon tax policy. The direct benefit of carbon policy comes from reducing many risks associated with climate change. The benefits associated with carbon abatement are difficult to estimate given the uncertainty in the extent and nature of economic harm associated with different levels of climate change. There is somewhat less uncertainty in the costs and co-benefits of climate policy. We can use these values - costs net of co-benefits - to bound the climate benefits required from a given policy. One can then identify where this implied climate benefit "hurdle" lies with respect to a distribution of independent estimates of climate benefits. Previous studies have shown co-benefit per ton estimates that rival policy costs. In a survey of 37 studies, Nemet et al. (2010) identified a median co-benefit per ton of $\$ 31$ with a wide range.

Concentrations of oxides of sulfur and nitrogen, particulate matter, and ozone are strongly driven by the burning of fossil fuels. Empirical studies (e.g., Holland, 2010) have identified the co-movement of fossil fuel combustion and pollution concentrations. The economic benefit of abating these pollutants is best understood via their impacts on health. For example, ambient concentrations of particulate matter have well-established adverse effects on respiratory health, which lead to higher medical expenses and loss in quality of life. 


\section{J. Woollacott}

The pathway from emissions reductions to monetized health benefits is complex. One must relate emissions to ambient concentrations by modeling the stoichiometry, transport, and deposition of pollutants taking place in the atmosphere. Given ambient concentrations, epidemiological evidence must inform the incidence of disease for a marginal change in ambient pollution. Finally, one must monetize the incidence of morbidity and mortality arising from such disease. Although these relationships are well-studied phenomena, the long causal chain induces uncertainty in the monetary estimates derived. Still, the estimates' order of magnitude and variation across policy scenarios can provide useful guidance to climate policy makers.

Full-scale atmospheric models such as Climatological Regional Dispersion Models (CRDM) or reduced-form approaches such as source-receptor matrices can map location-specific changes in emissions to changes in local and national ambient concentrations. Researchers have often relied on such reduced-form estimates in assessing the economic value of emissions reductions to avoid the prohibitive costs of full-scale models. For example, Fann et al. (2009) provide benefit-per-ton estimates for common non-GHG pollutants, Environmental Protection Agency and Department of Energy staff have relied on such estimates in regulatory impact assessments and other studies (e.g., Wind Vision, 2015; U.S. Environmental Protection Agency, 2015a), and the environmental economics literature contains numerous examples of such approaches (e.g., Burtraw et al., 2003; Muller and Mendelsohn, 2007; Groosman and Muller, 2011; Jaramillo and Muller, 2016).

Monetary values for changes in ambient concentrations are derived from the value of reduced morbidity (e.g., respiratory illness, emergency department admissions) and premature mortality events from pollution. The valuation of morbidity events considers medical expenditures, lost days of work, and individuals' willingness to pay to avoid the discomfort of illnesses. The valuation of mortality events relies on the value of a statistical life, $9.4 \mathrm{~mm}$ 2010\$ (U.S. Environmental Protection Agency, 2015b). The relatively high value of a statistical life leads to mortality costs strongly dominating morbidity costs in co-benefit valuations.

\subsection{Co-benefit modeling}

I relied on the COBRA screening model (US Environmental Protection Agency, 2015) to estimate the value of co-benefits. The COBRA model takes sector-specific percentage reductions in emissions of several non-GHG pollutants and reports county-level dollar impacts of those emissions changes. County-level results vary by source-receptor relationships between sector-specific emissions and ambient concentrations and are weighted by county-level populations. The COBRA model quantifies only the health benefits of reduced PM abated either directly or via its precursors, NOx and SO $x$.

The COBRA model provides high and low estimates of the benefits associated with certain benefit categories (adult mortality and nonfatal heart attacks). These benefit estimates vary based on the assumed sensitivity of health outcomes to pollution concentrations, "[s]pecifically, the high estimates are based on studies that estimated a 
larger effect of changes in ambient PM 2.5 levels on the incidence of these health effects" (US Environmental Protection Agency, 2015, p. 24).

The COBRA screening model does not quantify all health impacts associated with PM concentrations (e.g., cancer, strokes, and chronic bronchitis are not quantified). Reducing fossil fuel combustion will also generate a range of other health benefits, including those directly associated with $\mathrm{NO} x$ and $\mathrm{SO} x$ abatement, ozone abatement via $\mathrm{NO} x$ as a precursor, and from hazardous air pollutants such as mercury. Moreover, health consequences of air pollution are only part of the full suite co-benefits that would obtain under a carbon policy. For example, ozone formation and acidification from sulfur and carbon emissions alters agricultural productivity along with broader terrestrial and aquatic ecosystem dynamics. These systems convey valuable, though potentially nonmonetized, goods and services to us.

Independent of the direct hazards posed by an altered climate, climate change may ameliorate or exacerbate existing pollution exposures. For example, warmer temperatures could lead to increase in hazardous ozone concentrations even holding its precursors constant. One should therefore view the co-benefit assessment provided here as a significant but incomplete subset of the full suite of carbon policy co-benefits.

Co-benefits can be strongly heterogeneous, meaning national averages could mask significant variation in the benefits enjoyed by households across geography, income, and health. For example, reducing a ton of SOx emissions from the electric sector in California's San Joaquin valley carries 350,000 2006\$ in benefits versus just 6,300 2006\$ for the same reduction in Seattle, WA (Fann et al., 2009, Fig. 4). This variation depends on variations in local atmosphere, demographics, and health. Within a given geographic area, lower-income households may face higher exposures if they are more likely to work outdoors or less likely to be able to afford leaving the city for better air quality, meaning higher benefits to pollution abatement for these populations. Not all individuals carry the same likelihood of experiencing pollution-induced morbidity. Air pollution is likely to be particularly problematic for individuals already suffering from respiratory illnesses and less so for those in good health. The current analysis does not account for these factors.

The COBRA screening model provides a monetization of co-benefits that is statistical. The results provide the present value of a reduced likelihood of pollutionrelated morbidity or mortality. Reduced mortality risk accounts for the vast majority of benefits (99\%), so the tangible value of benefits is relatively small and comes from reduced medical expenditures for those suffering from pollution-related morbidities such as asthma or chronic obstructive pulmonary disease (COPD).

\section{Analysis}

\subsection{Costs analysis}

I run the ADAGE-US model to analyze the economic costs of five recycling mechanisms and six carbon price paths from the EMF-32 study for 30 total policy scenarios. Price trajectories were designed to start at a given value in the initial year of 
the policy (2020) and grow at one of two rates (1\% or 5\%). The initial price per ton of carbon was set to $\$ 25$ and $\$ 50$ growing at each rate, the social cost of carbon (growing at it's own rate), and an endogenously determined price to meet a $26 \%$ reduction in emissions relative to 2005 by 2025 (growing at $5 \%$ ). ${ }^{4}$

Carbon revenue was returned to household in a mix of three methods: lump-sum per household, capital tax reductions, and labor tax reductions. Households are grown according to Census Bureau Current Population Survey projections (2011). The first three designs returned all revenue by one of these mechanisms exclusively. The fourth divided the recycled revenue evenly between capital tax reductions and lump-sum rebates. The fifth provided equal percentage changes in labor and capital tax rates combined with lump-sum transfers to render the policy impact on the lowest income quintile households economically neutral.

To account for low-carbon alternatives, the ADAGE-US model includes the option for electric vehicle technologies and expanded substitution opportunities for electricity generation. Still, more low-carbon generation may be cost competitive than the model currently admits. Models with highly-detailed representations of carbon neutral and negative (e.g., bio-energy with carbon capture and sequestration) technologies for electricity generation are likely to report larger emissions reductions under the policies considered than ADAGE-US. ADAGE-US thereby conveys some degree of conservatism with respect to the costs of transitioning to and scaling renewable alternatives.

\subsection{Co-benefits analysis}

To assess the co-benefits of climate policy, I map ADAGE-US and COBRA sectors and then input percentage reductions in fossil fuel combustion into COBRA as emissions reductions, implying fixed emissions factors. I take the percentage change in the net present value of fuel use over the policy period and input it for the COBRA model analysis year, 2017. This approach discounts the marginal benefit of additional abatement that will not occur until future periods. The mapping is imperfect but provides a reasonable first-order approximation to the percentage reductions for the COBRA sectors. These reductions are fuel-specific for the electricity and manufacturing sectors. I provide the COBRA model with percentage reductions in PM 2.5, SO2, and NOx based on percentage reductions in fossil fuel consumption from the ADAGE-US results.

Applying percentage reductions in this way assumes that the fossil fuel emissions rates for the different pollutants from each sector will remain constant as the energy system adapts to the carbon policy. This assumption is reasonable for oil and gas combustion, for which a limited set of pollution control technologies are utilized, but less accurate for coal given the multiplicity of pollution control technologies employed for cleaner combustion. Still, the screening model can provide a useful first-order approximation of the co-benefits of carbon policy.

\footnotetext{
${ }^{4}$ The social cost of carbon was set at 44 in 2020 and grew at approximately $1.7 \%$ per year.
} 
The COBRA model provides two rates for discounting, 3\% and 7\%. The discount rate for ADAGE-US households is 5\%. For conservatism, I present results using COBRA's $7 \%$ rate; however, given the front-loading of co-benefits, the total co-benefit value is not particularly sensitive to the discount rate. Co-benefit values are approximately $10 \%$ higher when valued with the $3 \%$ rate. Although valuing at this rate is not an option in COBRA, interpolating between the $3 \%$ and $7 \%$ rates suggests that co-benefits discounted at $5 \%$ would be slightly more than $5 \%$ higher than those discounted at $7 \%$.

\section{Results}

\subsection{Emissions}

The primary goal of climate policy is to reduce GHG emissions. Results from ADAGE-US and other models in this study (Macaluso et al., 2018) show that emissions are most sensitive to the size of the carbon tax applied and relatively insensitive to how the revenue is recycled. Figure 2 presents baseline levels and percent changes in GHGs for four scenarios: lump-sum and lump-sum with capital tax rebates at \$25 and $\$ 50$, both growing at $5 \%$. Total emissions levels and changes are the combined result of, in descending order, changes in the aggregate emissions intensity of energy use, the energy used per unit of economic activity, and the change in economic activity (given as output here). Declining emissions intensity indicates that the policies induce substitution toward less carbon-intensive energy sources, such as natural gas and renewables. Declining energy per unit output ratios indicate that the policy has induced greater energy efficiency in production and consumption.

The next subsection explains how I relate emissions reductions of non-GHG pollutants to fossil fuel use and limitations of this approach. Figure 3 presents the

\begin{tabular}{lrr}
\hline & $\$ 25$ at 5\% & \$50 at 5\% \\
Baseline (2020-2040 NPV) & & \\
Emissions / energy (Bn. Tn. / EJ) & 0.28 & 0.28 \\
Energy / output (EJ / Tril. \$) & 0.57 & 0.57 \\
Output (Tril. \$) & 459.8 & 459.8 \\
$\quad$ Emissions (Bn. Tonnes) & 74.2 & 74.2 \\
Percent change from baseline & & \\
Lump-sum & & \\
Emissions / energy & $-15.3 \%$ & $-18.4 \%$ \\
Energy / output & $-10.2 \%$ & $-16.8 \%$ \\
Output & $-1.5 \%$ & $-2.3 \%$ \\
$\quad$ Emissions & $-25.1 \%$ & $-33.7 \%$ \\
Lump-sum \& Capital & & \\
Emissions / energy & $-16.1 \%$ & $-20.0 \%$ \\
$\quad$ Energy / output & $-10.0 \%$ & $-16.4 \%$ \\
Output & $-0.7 \%$ & $-0.1 \%$ \\
$\quad$ Emissions & $-24.3 \%$ & $-32.4 \%$ \\
\hline
\end{tabular}

Figure 2. Decomposition of changes in the NPV of CO2 emissions under the policy. 


\begin{tabular}{|c|c|c|c|c|}
\hline \multirow[b]{2}{*}{ COBRA Sector } & \multirow[b]{2}{*}{ Fuel } & \multicolumn{2}{|c|}{ Lump-sum } & $\begin{array}{l}\text { Lump-sum } \\
+ \text { Capital }\end{array}$ \\
\hline & & $\$ 25$ at $5 \%$ & $\$ 50$ at $5 \%$ & $\$ 25$ at $5 \%$ \\
\hline \multirow[t]{3}{*}{ Electricity } & Coal & $-60.2 \%$ & $-74.7 \%$ & $-60.7 \%$ \\
\hline & Oil & $-32.9 \%$ & $-46.4 \%$ & $-33.2 \%$ \\
\hline & Gas & $-16.4 \%$ & $-30.2 \%$ & $-17.0 \%$ \\
\hline \multirow[t]{3}{*}{ Industrial fuel combustion } & Coal & $-28.2 \%$ & $-36.1 \%$ & $-27.4 \%$ \\
\hline & Oil & $-3.4 \%$ & $-6.8 \%$ & $-1.7 \%$ \\
\hline & Gas & $-12.4 \%$ & $-19.7 \%$ & $-11.1 \%$ \\
\hline Chemicals & All fossil & $-11.9 \%$ & $-18.3 \%$ & $-10.4 \%$ \\
\hline Other fuel combustion & & $-5.0 \%$ & $-7.4 \%$ & $-3.9 \%$ \\
\hline Highway vehicles & & $-3.3 \%$ & $-6.3 \%$ & $-2.8 \%$ \\
\hline Lightduty highway vehicles & & $-3.0 \%$ & $-6.5 \%$ & $-2.9 \%$ \\
\hline Metals processing & & $-11.9 \%$ & $-18.3 \%$ & $-10.4 \%$ \\
\hline Agriculture & & $-4.1 \%$ & $-7.7 \%$ & $-3.4 \%$ \\
\hline Off-highway vehicles & & $-3.3 \%$ & $-6.3 \%$ & $-2.8 \%$ \\
\hline Other industrial processes & & $-11.9 \%$ & $-18.3 \%$ & $-10.4 \%$ \\
\hline Petroleum related industries & & $-3.0 \%$ & $-6.1 \%$ & $-2.6 \%$ \\
\hline Solvent uses & & $-11.9 \%$ & $-18.3 \%$ & $-10.4 \%$ \\
\hline Storage and transport & & $-3.3 \%$ & $-6.3 \%$ & $-2.8 \%$ \\
\hline Waste disposal & & $-5.0 \%$ & $-7.4 \%$ & $-3.9 \%$ \\
\hline
\end{tabular}

Figure 3. Percent change in NPV of fuel use by COBRA sector and policy.

reductions in fossil fuel use by COBRA model sector and, for some sectors, fuel (the COBRA model only takes fuel-specific inputs for certain sectors). Similar to GHG emissions, percent changes in fuel use are less sensitive to revenue recycling than to the level of the tax. The largest percent changes occur in the electric sector, where dramatic reductions in coal use are partly offset by much more modest reductions in natural gas relative to the baseline AEO projection. I present percentage reductions in Fig. 3 at the national level and, despite some regional heterogeneity, results from national-level COBRA inputs do not differ significantly from results from regionspecific COBRA inputs.

\subsection{Co-benefits}

In this section, I present the co-benefits estimated from the COBRA model in aggregate and at the level of a representative household. As the co-benefit results are largely insensitive to the recycling scenario, I focus on results for the lump-sum scenarios for simplicity. Figure 4 shows the national co-benefits of the $\$ 25$ taxes with lump-sum recycling ranging from 72-162 billion 2016 or \$547-1234 per household (un-adjusted for head-count). Mortality impacts range between 8,559 and 19,329 deaths and account for nearly all $(98.6 \%)$ of the monetary benefits considered in COBRA at a county and national level. Still, at 1.5-2 billion 2016\$, the morbidity cobenefits are nontrivial. Figure 5 shows how the co-benefits vary considerably by tax level but are relatively insensitive to the recycling mechanism. A doubling of the tax 


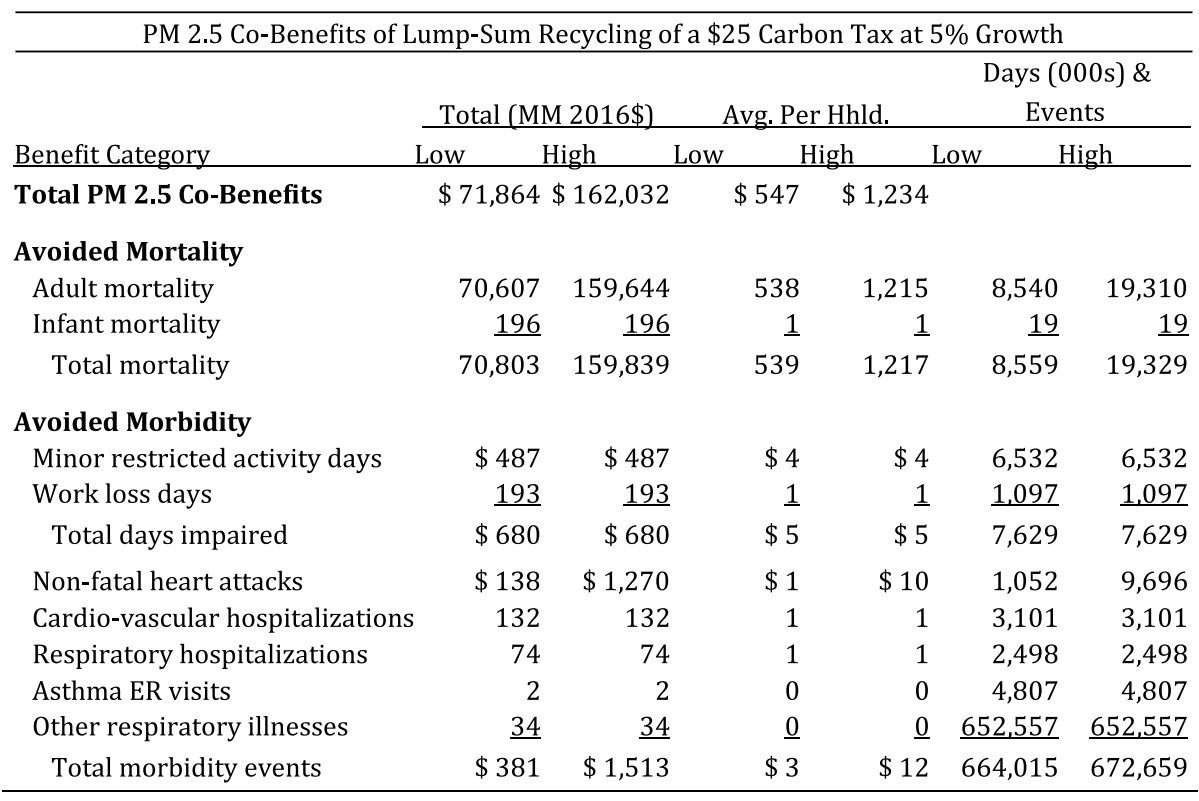

Figure 4. Detailed PM 2.5 co-benefits of carbon taxes by benefit.

rate leads to less than twice the amount of abatement, which is evident in the co-benefit totals in Fig. 5. Changing the recycling method has a very slight impact on the cobenefits estimate, well within the margin of error for these estimates (see Fig. 5).

The COBRA model generates county-level dollar-value estimates of reduced mortality and morbidity benefit associated with the emissions reductions. Figure 6 shows considerable spatial variation in co-benefits (from a $25 \$$ at $5 \%$ policy). Cobenefits depend on county-level changes in ambient concentrations and the county populations that are exposed to them. On a per household basis, the largest benefits of the policy are in the thousands per household, spanning the region between the Mississippi river and Appalachian mountains, from northeast Arkansas to

\begin{tabular}{|c|c|c|c|c|c|c|c|}
\hline \multicolumn{8}{|c|}{ Total PM 2.5 Co-Benefits of Different Carbon Tax Scenarios } \\
\hline \multirow[b]{2}{*}{ Policy } & \multirow[b]{2}{*}{ BenefitCategory } & \multicolumn{2}{|c|}{ Total (MM 2016\$) } & \multicolumn{2}{|c|}{ Avg. Per Hhld. } & \multicolumn{2}{|c|}{ Mortality Events } \\
\hline & & Low & High & Low & High & Low & High \\
\hline$\$ 25 @ 5 \%$ & Total PM 2.5 Co-Benefits & $\$ 71,864$ & $\$ 162,032$ & $\$ 547$ & $\$ 1,234$ & & \\
\hline \multirow[t]{2}{*}{ Lump-sum } & Avoidedmortality & 70,803 & 159,839 & 539 & 1,217 & 8,559 & 19,329 \\
\hline & Avoided morbidity & 1,061 & 2,193 & 8 & 17 & & \\
\hline$\$ 50 @ 5 \%$ & Total PM 2.5 Co-Benefits & $\$ 97,644$ & $\$ 219,946$ & $\$ 743$ & $\$ 1,675$ & & \\
\hline \multirow[t]{2}{*}{ Lump-sum } & Avoidedmortality & 96,198 & 216,968 & 732 & 1,652 & 11,629 & 26,237 \\
\hline & Avoided morbidity & 1,446 & 2,978 & 11 & 23 & & \\
\hline$\$ 25 @ 5 \%$ & Total PM 2.5 Co-Benefits & $\$ 70,591$ & $\$ 159,168$ & $\$ 537$ & $\$ 1,212$ & & \\
\hline Capital-tax +lump- & Avoided mortality & 69,550 & 157,015 & 530 & 1,195 & 8,408 & 18,987 \\
\hline $\operatorname{sum}(50 / 50)$ & Avoided morbidity & 1,041 & 2,154 & 8 & 16 & & \\
\hline
\end{tabular}

Figure 5. Summary PM 2.5 co-benefits of carbon taxes by scenario. 
Mortaility \& morbidity cost savings per household (2016\$)

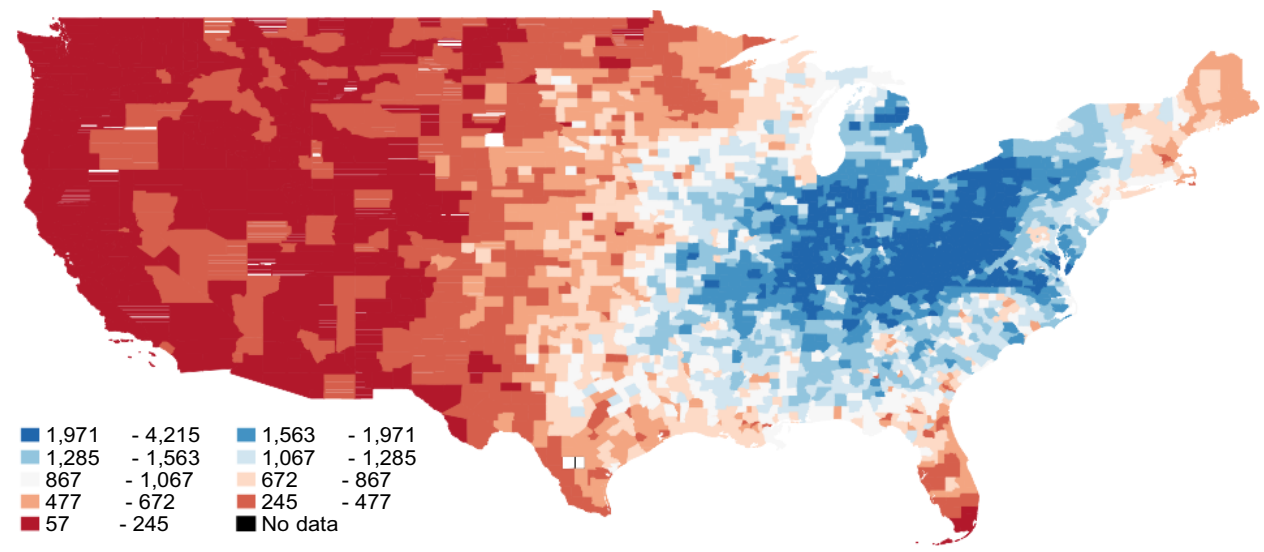

Figure 6. County-level per-household co-benefits of a $\$ 25 / \mathrm{tCO}_{2}$ tax.

\begin{tabular}{|c|c|c|c|c|c|c|c|c|c|}
\hline \multirow[b]{4}{*}{ Quintile } & \multicolumn{9}{|c|}{ Regions } \\
\hline & New & Middle & E. North & W. North & South & E. South & W. South & & \\
\hline & England & Atlantic & Central & Central & Atlantic & Central & Central & Mountain & Pacific \\
\hline & NEG & MID & ENC & WNC & SAC & ESC & WSC & MTN & PAC \\
\hline Q1: <25K & $\$ 724$ & $\$ 1,163$ & $\$ 1,367$ & $\$ 713$ & $\$ 868$ & $\$ 1,389$ & $\$ 586$ & $\$ 169$ & $\$ 196$ \\
\hline Q2: $25-50 \mathrm{~K}$ & $\$ 716$ & $\$ 1,172$ & $\$ 1,360$ & $\$ 687$ & $\$ 883$ & $\$ 1,383$ & $\$ 581$ & $\$ 167$ & $\$ 194$ \\
\hline Q3: $50-75 \mathrm{~K}$ & $\$ 716$ & $\$ 1,166$ & $\$ 1,347$ & $\$ 677$ & $\$ 901$ & $\$ 1,393$ & $\$ 583$ & $\$ 169$ & $\$ 194$ \\
\hline Q4: 75-100K & $\$ 719$ & $\$ 1,165$ & $\$ 1,331$ & $\$ 660$ & $\$ 908$ & $\$ 1,383$ & $\$ 580$ & $\$ 169$ & $\$ 194$ \\
\hline Q5: $100 \mathrm{~K}+$ & $\$ 702$ & $\$ 1,085$ & $\$ 1,255$ & $\$ 622$ & $\$ 847$ & $\$ 1,317$ & $\$ 549$ & $\$ 164$ & $\$ 200$ \\
\hline
\end{tabular}

Figure 7. Distribution of per-household co-benefits by region and income for a $\$ 25$ tax growing at $5 \%$ with lump-sum recycling.

southwestern New York. In general, per household benefits are low in the rocky mountain and Pacific coast states, ranging in the low hundreds of dollars per household or less.

Figure 7 shows the regional and economic variation of co-benefits on a perhousehold basis. The COBRA utility does not distinguish co-benefits by income. I did examine spatial sorting of households at the county and quintile level and found little visually discernible pattern to these results. That is, there does not appear to be enough county-level economic segregation to drive noticeable differences in benefits across income groups. Sub-county variations in exposure and spatial sorting by different income groups may still drive differences in the co-benefits enjoyed by those groups under the policy, but the COBRA model assumes constant benefits at a county level.

\subsection{Gross policy costs}

I examine welfare outcomes for 81 representative households from the ADAGE-US model aggregated into quintiles for a total of 45 households. The distribution of 


\begin{tabular}{|c|c|c|c|c|c|c|c|c|c|c|}
\hline & $\begin{array}{l}\text { New } \\
\text { England }\end{array}$ & $\begin{array}{l}\text { Middle } \\
\text { Atlantic } \\
\end{array}$ & $\begin{array}{l}\text { E. North } \\
\text { Central } \\
\end{array}$ & $\begin{array}{l}\text { W. North } \\
\text { Central }\end{array}$ & $\begin{array}{l}\text { South } \\
\text { Atlantic }\end{array}$ & $\begin{array}{l}\text { E. South } \\
\text { Central }\end{array}$ & $\begin{array}{l}\text { W. South } \\
\text { Central }\end{array}$ & Mountain & Pacific & $\begin{array}{l}\text { National } \\
\$ \text {-Equiv. }\end{array}$ \\
\hline Lump-sum & NEG & MID & ENC & WNC & SAC & ESC & WSC & MTN & PAC & USA \\
\hline $\mathrm{Q} 1:<25 \mathrm{~K}$ & $-0.1 \%$ & $0.0 \%$ & $-0.1 \%$ & $-0.2 \%$ & $-0.1 \%$ & $-0.1 \%$ & $0.1 \%$ & $0.0 \%$ & $0.1 \%$ & $-\$ 3$ \\
\hline Q2: $25-50 \mathrm{~K}$ & $-0.3 \%$ & $-0.3 \%$ & $-0.4 \%$ & $-0.5 \%$ & $-0.4 \%$ & $-0.5 \%$ & $-0.5 \%$ & $-0.4 \%$ & $-0.1 \%$ & $-\$ 121$ \\
\hline Q3: 50-75K & $-0.4 \%$ & $-0.3 \%$ & $-0.6 \%$ & $-0.6 \%$ & $-0.5 \%$ & $-0.7 \%$ & $-0.8 \%$ & $-0.5 \%$ & $-0.2 \%$ & $-\$ 270$ \\
\hline Q4: $75-100 \mathrm{~K}$ & $-0.4 \%$ & $-0.4 \%$ & $-0.7 \%$ & $-0.6 \%$ & $-0.4 \%$ & $-0.7 \%$ & $-1.0 \%$ & $-0.5 \%$ & $-0.3 \%$ & $-\$ 498$ \\
\hline Q5: 100K+ & $-0.3 \%$ & $-0.4 \%$ & $-0.7 \%$ & $-0.6 \%$ & $-0.4 \%$ & $-0.8 \%$ & $-1.3 \%$ & $-0.5 \%$ & $-0.2 \%$ & $-\$ 1,063$ \\
\hline
\end{tabular}

\begin{tabular}{|c|c|c|c|c|c|c|c|c|c|c|}
\hline \multicolumn{11}{|l|}{ Capital-tax } \\
\hline$\overline{Q 1:<25 K}$ & $-0.4 \%$ & $-0.4 \%$ & $-0.5 \%$ & $-0.5 \%$ & $-0.4 \%$ & $-0.4 \%$ & $-0.2 \%$ & $-0.4 \%$ & $-0.3 \%$ & $-\$ 45$ \\
\hline Q2: $25-50 \mathrm{~K}$ & $-0.2 \%$ & $-0.2 \%$ & $-0.4 \%$ & $-0.4 \%$ & $-0.3 \%$ & $-0.4 \%$ & $-0.4 \%$ & $-0.3 \%$ & $-0.1 \%$ & $-\$ 95$ \\
\hline Q3: 50-75K & $-0.1 \%$ & $-0.1 \%$ & $-0.3 \%$ & $-0.3 \%$ & $-0.2 \%$ & $-0.3 \%$ & $-0.6 \%$ & $-0.2 \%$ & $0.1 \%$ & $-\$ 119$ \\
\hline Q4: $75-100 \mathrm{~K}$ & $0.0 \%$ & $0.0 \%$ & $-0.3 \%$ & $-0.3 \%$ & $-0.1 \%$ & $-0.3 \%$ & $-0.6 \%$ & $-0.1 \%$ & $0.2 \%$ & $-\$ 138$ \\
\hline Q5: 100K+ & $0.3 \%$ & $0.2 \%$ & $-0.1 \%$ & $-0.1 \%$ & $0.1 \%$ & $-0.2 \%$ & $-0.8 \%$ & $0.0 \%$ & $0.4 \%$ & $\$ 63$ \\
\hline
\end{tabular}

\begin{tabular}{|c|c|c|c|c|c|c|c|c|c|c|}
\hline \multicolumn{11}{|c|}{ Capital-tax + lump-sum $(50 / 50)$} \\
\hline$\overline{\mathrm{Q} 1:<25 \mathrm{~K}}$ & $-0.3 \%$ & $-0.2 \%$ & $-0.3 \%$ & $-0.3 \%$ & $-0.2 \%$ & $-0.2 \%$ & $0.0 \%$ & $-0.2 \%$ & $-0.1 \%$ & $-\$ 23$ \\
\hline Q2: $25-50 \mathrm{~K}$ & $-0.3 \%$ & $-0.2 \%$ & $-0.4 \%$ & $-0.4 \%$ & $-0.3 \%$ & $-0.4 \%$ & $-0.4 \%$ & $-0.3 \%$ & $-0.1 \%$ & $-\$ 106$ \\
\hline Q3: 50-75K & $-0.2 \%$ & $-0.2 \%$ & $-0.4 \%$ & $-0.4 \%$ & $-0.3 \%$ & $-0.5 \%$ & $-0.7 \%$ & $-0.3 \%$ & $-0.1 \%$ & $-\$ 192$ \\
\hline Q4: $75-100 \mathrm{~K}$ & $-0.2 \%$ & $-0.2 \%$ & $-0.5 \%$ & $-0.4 \%$ & $-0.3 \%$ & $-0.5 \%$ & $-0.8 \%$ & $-0.3 \%$ & $-0.1 \%$ & $-\$ 314$ \\
\hline Q5: 100K+ & $0.0 \%$ & $-0.1 \%$ & $-0.4 \%$ & $-0.3 \%$ & $-0.2 \%$ & $-0.5 \%$ & $-1.1 \%$ & $-0.3 \%$ & $0.1 \%$ & $-\$ 494$ \\
\hline
\end{tabular}

\begin{tabular}{|c|c|c|c|c|c|c|c|c|c|c|}
\hline Q1: $<25 \mathrm{~K}$ & $0.0 \%$ & $0.0 \%$ & $0.0 \%$ & $0.0 \%$ & $0.0 \%$ & $0.0 \%$ & $0.0 \%$ & $0.0 \%$ & $0.0 \%$ & $\$ 0$ \\
\hline Q2: $25-50 \mathrm{~K}$ & $-0.6 \%$ & $-0.6 \%$ & $-0.7 \%$ & $-0.7 \%$ & $-0.7 \%$ & $-0.7 \%$ & $-0.7 \%$ & $-0.7 \%$ & $-0.5 \%$ & $-\$ 210$ \\
\hline Q3: 50-75K & $-0.4 \%$ & $-0.3 \%$ & $-0.6 \%$ & $-0.6 \%$ & $-0.5 \%$ & $-0.7 \%$ & $-0.9 \%$ & $-0.5 \%$ & $-0.2 \%$ & $-\$ 273$ \\
\hline Q4: 75-100K & $-0.2 \%$ & $-0.2 \%$ & $-0.5 \%$ & $-0.5 \%$ & $-0.3 \%$ & $-0.6 \%$ & $-0.9 \%$ & $-0.4 \%$ & $-0.1 \%$ & $-\$ 352$ \\
\hline Q5: 100K+ & $0.1 \%$ & $0.1 \%$ & $-0.3 \%$ & $-0.2 \%$ & $0.0 \%$ & $-0.5 \%$ & $-1.0 \%$ & $-0.2 \%$ & $0.2 \%$ & $-\$ 234$ \\
\hline
\end{tabular}

Figure 8. Policy impacts by household for certain recycling scenarios with $\$ 25$ tax growing at $5 \%$.

outcomes for households varies considerably depending on the recycling scheme. Lump-sum recycling tends to favor lower-income households as a fixed amount per household will deliver a higher marginal benefit to lower-income households than to higher-income households. Lump-sum payments also impose the highest aggregate welfare loss on society as they provide no direct incentive effects to supply more labor or capital to production, thereby offsetting losses in GDP.

Figure 8 shows the percentage welfare changes experienced by representative households for each quintile in each region. At the national level, I multiply percent welfare changes by the average income for the quintile (2016\$) to provide an approximation of the scale of impact in the last "National \$-equivalent" column (average income by quintile are from Urban Institute and Brookings Institution Tax Policy Center (2017)). The cells of the table are shaded according to their values, with larger values darker. As they are in percent terms, the shading gives an indication of the relative regressivity of each recycling scheme. Lump-sum rebates are least regressive, capital tax rebates are most regressive, and the mixed capital and lump-sum rebates are mostly neutral.

Spatial variation in welfare outcomes is apparent across scenarios, with coastal regions experiencing lower welfare losses than inland regions. This is easiest to see in 


\section{J. Woollacott}

the mixed capital and lump-sum scenario where the income gradient is slightest. I extend the cost analysis to the county level by applying region-specific percent changes in welfare to the per-household adjusted gross income reported for each quintile in each county. (Income by county and quintile are available from the Internal Revenue Service (2014)) I present these results with the net policy assessment in the next section, where I focus on the scenario modeling a $\$ 25$ tax growing at 5\% with revenue recycled evenly to lump-sum and capital tax rebates.

\subsection{Net policy assessment}

By approximating county-level welfare cost estimates, I can compare the spatial variation in co-benefits net of the policy costs. Figures 9-13 map the county-level gross and net (of co-benefit) costs by quintile. I excluded three of 3078 counties (contiguous US) as outliers. ${ }^{5}$ Including these observations would significantly widen the value bins for the maps presented, masking relevant variation. For parsimony, I focus on results for the $\$ 25$ at 5\% tax with both lump-sum and capital rebates policy. As discussed

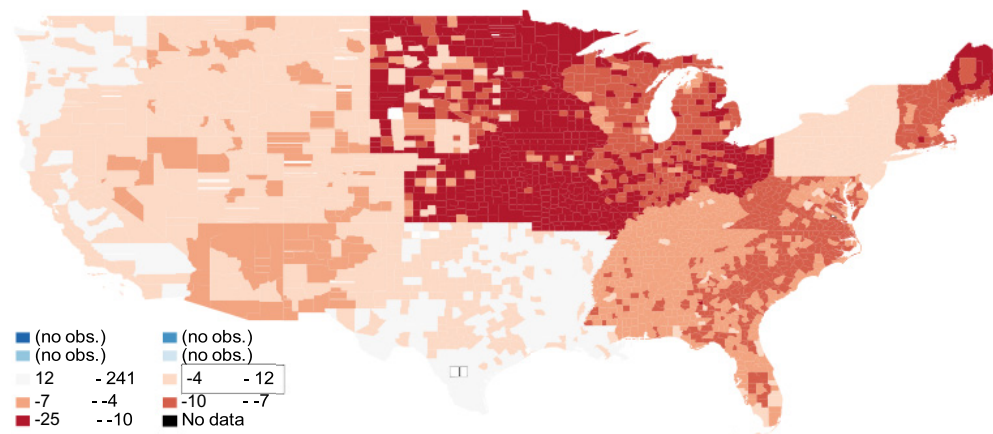

Gross

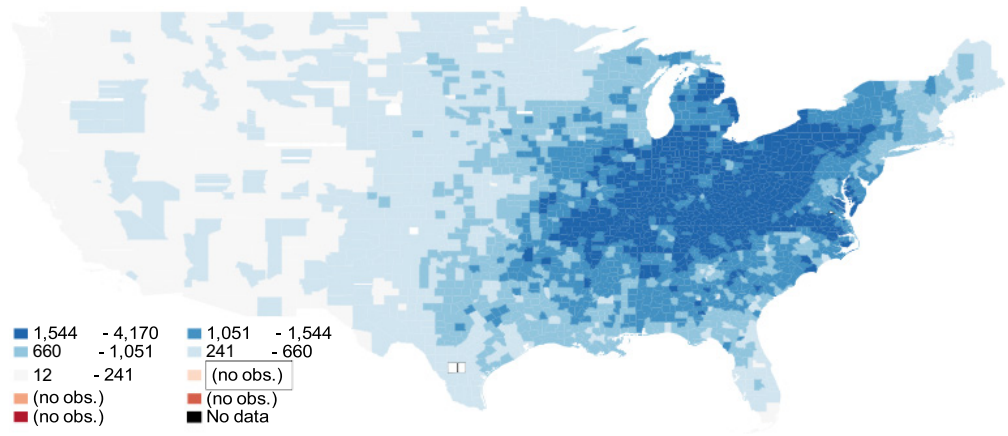

Net

Figure 9. Q1 household welfare impact, \$25 at 5\% tax with both lump-sum and capital rebates.

\footnotetext{
${ }^{5}$ Benefits for Charles City, VA, an unincorporated community in eastern Virginia, are exceptionally large on a per household basis at $91432016 \$$ per household (13 standard deviations outside the mean). Incomes, and therefore gross impacts, in McMullen and adjacent La Salle counties Texas, south of San Antonio, are also exceptionally large at approximately $1,050,0002016 \$$ (17 standard deviations outside the mean for fifth-quintile households).
} 


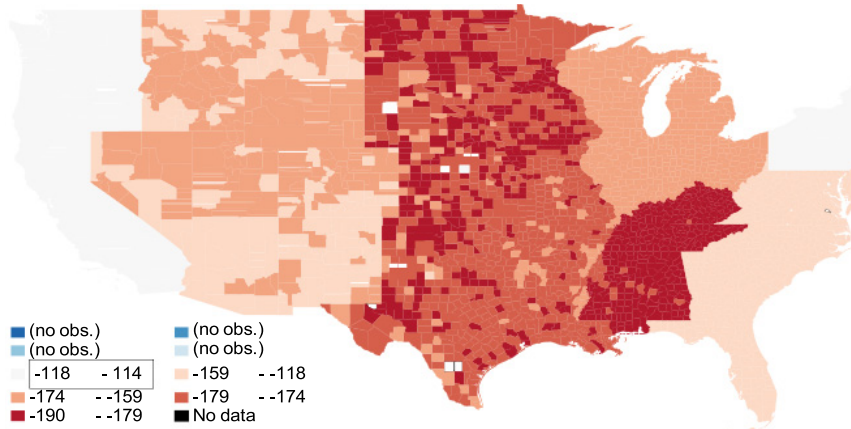

Gross

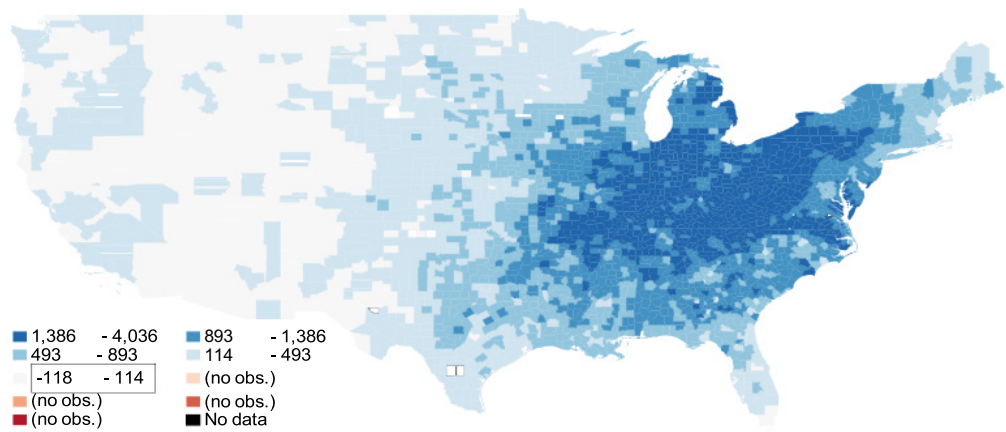

Net

Figure 10. Q2 household welfare impact, \$25 at 5\% tax with both lump-sum and capital rebates.

above, co-benefits results are relatively insensitive to the recycling scheme and scale linearly with the tax rate. The distribution of welfare costs is most neutral for the lumpsum plus capital-tax rebate, matching the income-neutral distribution of co-benefits. (I present results for the lump-sum scenario in the supplemental information.)

The net and gross map for each quintile are presented on the same choropleth scales for comparison, and the zero point of the scale is outlined in the legend. Bin sizes are set at the quantile cut points. Since netting co-benefits shifts the county values upward and the choropleth scale is fixed, higher-value bins in the gross cost map have no observations. The value bins are based on quantiles of the full range of gross and net data.

The regional representation of welfare costs is evident in the maps by the relative lack of intraregional variation in the gross welfare maps. Variation in the county-level distribution of per-household incomes within the quintile are responsible for the depicted variation in gross costs. For example, in the two southernmost counties of California, as of 2014, the average income of households in the first quintile in San Diego was 6762 versus 12,308 2016\$ in Imperial county (Internal Revenue Service, 2014), just one county east. In this example, an equal percentage equivalent variation of $0.1 \%$ for first-quintile households in the Pacific region results in different household impacts at the county level. 


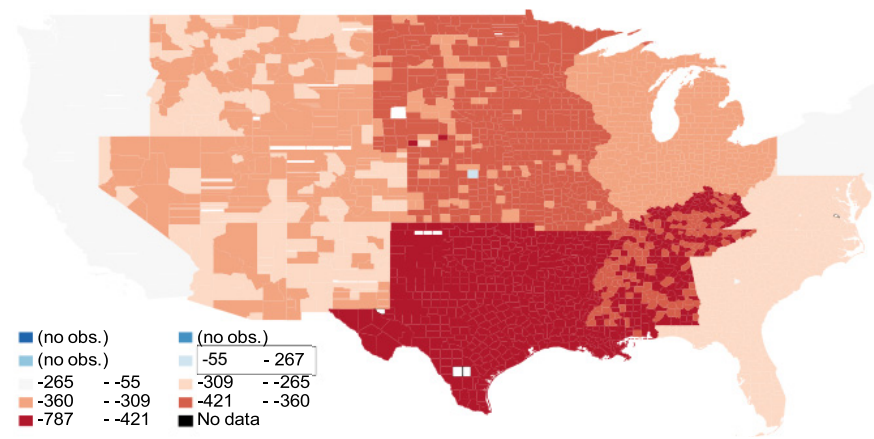

Gross

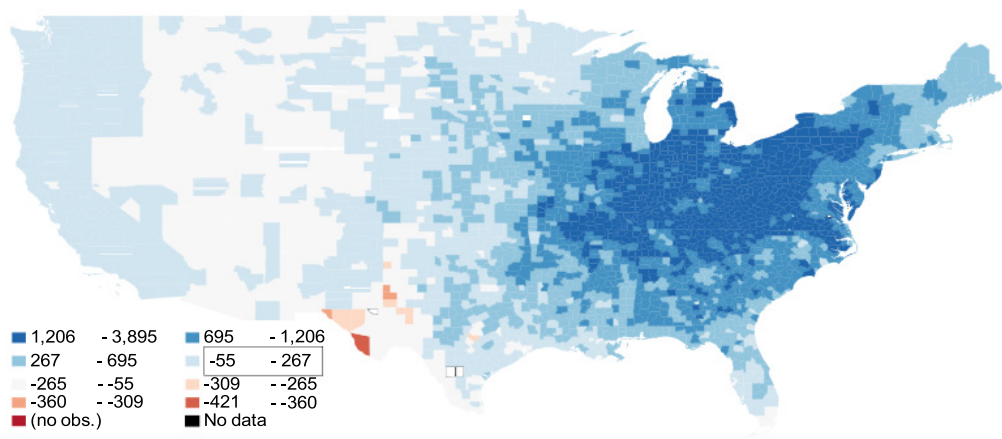

Net

Figure 11. Q3 household welfare impact, \$25 at 5\% tax with both lump-sum and capital rebates.

The side-by-side comparisons of gross and net-of-co-benefits impacts in Figs. 9-13 show how, particularly for lower-income households, the value of policy co-benefits can overwhelm the value of its costs. ${ }^{6}$ For example, county-level outcomes for the first and second quintiles go from near or less than zero to near or greater than zero when considering co-benefits. This pattern is weaker for higher-income households, whose economic costs are relatively larger but whose co-benefits remain largely the same. This weaker pattern is apparent in the figure where the regional boundaries that dominate the economic costs are still visible in many places with co-benefits netted out, whereas those boundaries all but disappear for lower-income households. The cobenefits are relatively progressive, but their nonmonetary value cannot directly offset the monetary costs associated with higher prices and lower incomes.

\subsection{Efficiency analysis}

The economic efficiency criterion for cost-benefit analyses hinges on the equivalence of marginal costs and benefits. The marginal costs are clear from the data produced in this study, while the marginal climate benefits are less so. Netting the co-benefit of climate policy against its marginal cost provides an upper bound on the required

${ }^{6}$ The maps in Figs. 9-13 will provide higher resolution when zoomed. 


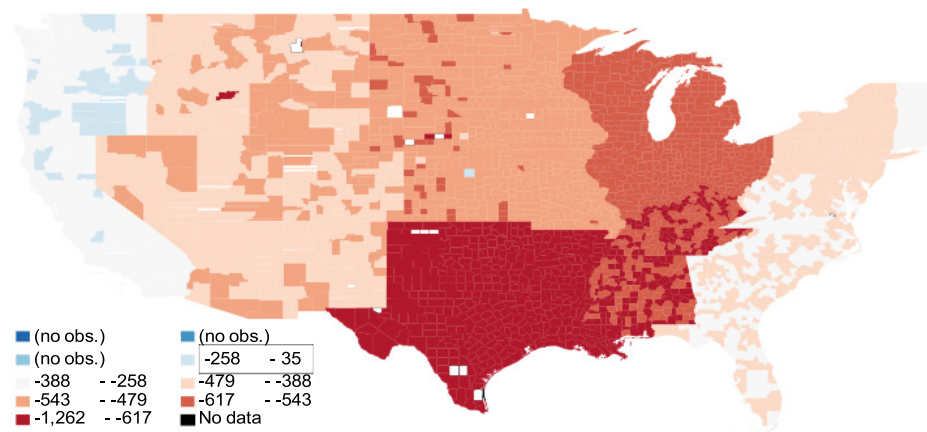

Gross

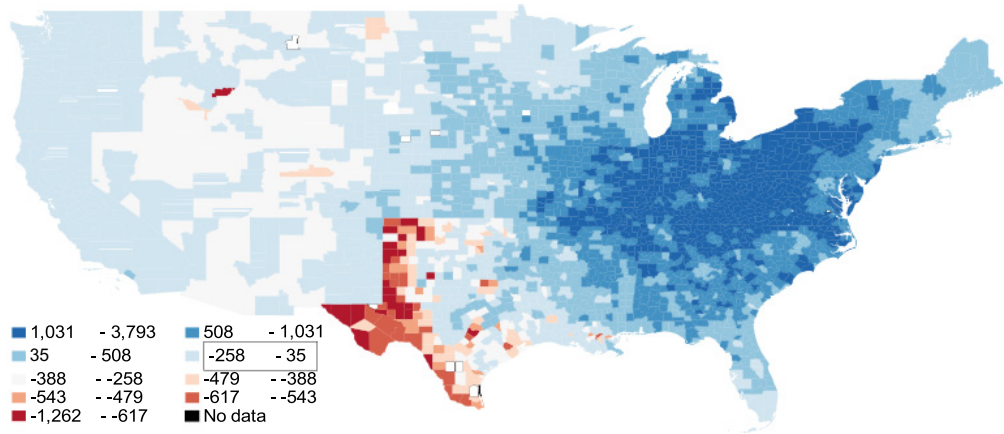

Net

Figure 12. Q4 household welfare impact, \$25 at 5\% tax with both lump-sum and capital rebates.

marginal climate benefit of abating $\mathrm{CO}_{2}$ since many other co-benefits have not been accounted.

The COBRA model applies a constant marginal benefit to non-GHG emissions reductions, implying equal average and marginal benefits. For the purposes of this analysis, I divide total policy co-benefits by tons of abated carbon, both in net present value at a rate of $7 \%$ for consistency with co-benefits discounting. As an extension, one could parametrize a marginal benefit curve for non-GHG pollutants with diminishing returns, but such analysis is beyond the scope of the current work.

Figure 14 shows the marginal welfare cost and average co-benefit of the carbon policy where revenue is recycled through both lump-sum and capital tax rebates. To generate the range of abatement presented, I modeled a range of carbon taxes from $\$ 20-30 / \mathrm{tCO}_{2}$ growing at $5 \%$ in $\$ 0.25$ increments. I then divide the change in welfare costs by the change in carbon emissions (both in net present value) at each increment for a discrete approximation of the marginal welfare cost. For two of those 41 runs, emissions did not change, which distorted the marginal welfare cost calculation. As such, these observations and those immediately following are omitted from the figures.

Marginal welfare costs range $\$ 45-75$ over a range of 23-28\% abatement of $\mathrm{CO}_{2}$ at a national level for the \$20-30 carbon taxes considered. Over the range of US abatement considered under these policies, the marginal welfare costs identified here are consistent with those found in other work (e.g., Morris et al., 2012). The marginal 


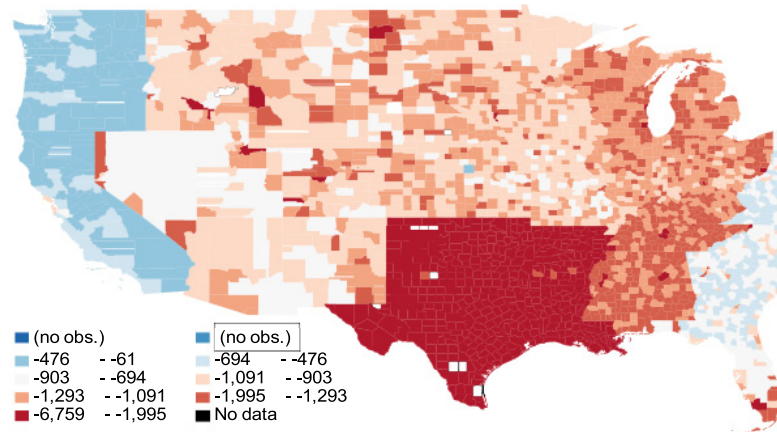

Gross

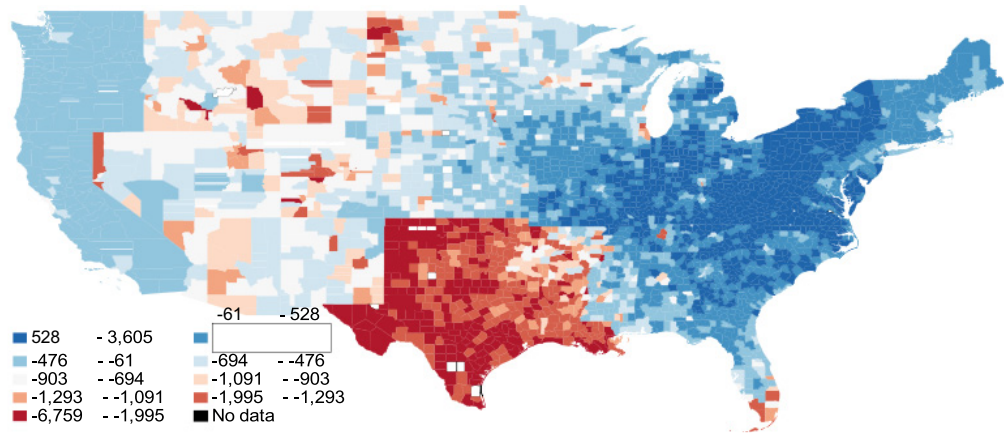

Net

Figure 13. Q5 household welfare impact, $\$ 25$ at 5\% tax both with lump-sum and capital rebates.

(set equal to average) co-benefit of $\$ 31 / \mathrm{tCO}_{2}$ is consistent with those reported in Nemet et al.'s (2010) survey. It offsets more than half of the $\$ 58 / \mathrm{tCO}_{2}$ marginal welfare cost at the midpoint. The co-benefits considered here are incomplete, so the residual $\$ 27 / \mathrm{tCO}_{2}$ in marginal welfare cost is an upper bound on the hurdle, the policy's climate benefits must be clear to suggest the policy is worth undertaking at this level of abatement.

The results in Fig. 14 mask significant regional variation in the marginal welfare costs and co-benefits, shown in Fig. 15. Regional variation in welfare costs reflect inter-regional variation in the carbon intensity of income and expenditure patterns, and the production processes that support them. Marginal co-benefits range from $\$ 5-257 / \mathrm{tCO}_{2}$ and welfare costs from $\$-176-114 / \mathrm{tCO}_{2}$. Negative marginal welfare costs in the Pacific region suggest that the policy should be undertaken regardless of any climate benefits or co-benefit, however, the results cannot be considered in isolation. The regional marginal costs and co-benefits reflect the impact of each region and all other regions undertaking the policy. Co-benefits are highest in New England (NEG), a region downwind of pollution from other states, a perpetually vexing problem for air policies regulated under state federalism. The Mid-Atlantic (MID) region is the third region where the policy co-benefits outstrip its marginal welfare costs, and these three regions do comparatively less abatement in percentage terms $(10 \%)$ than the remaining six $(30 \%)$. 


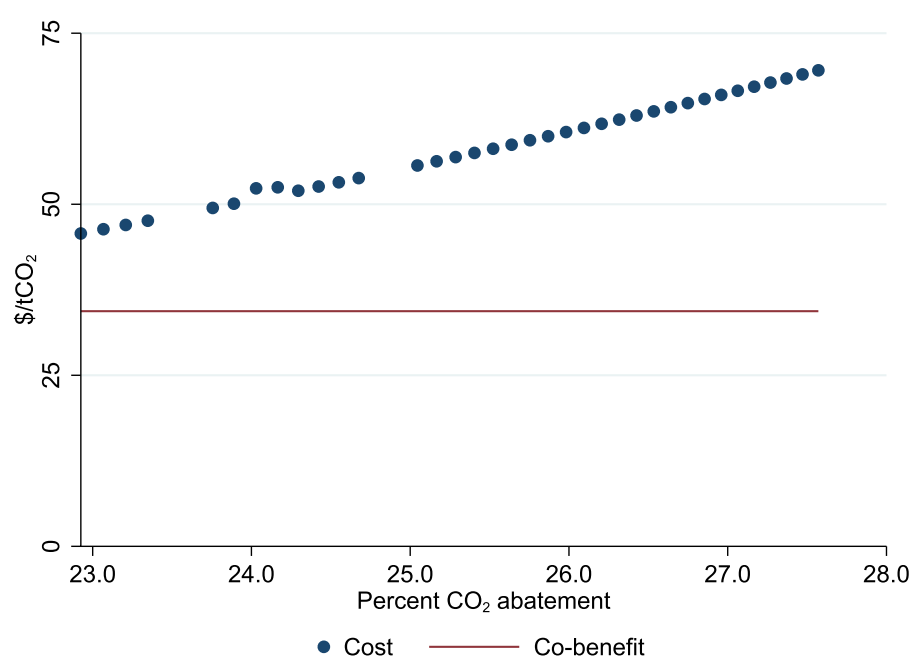

Figure 14. Marginal welfare cost and average co-benefit of $\mathrm{CO}_{2}$ abatement.
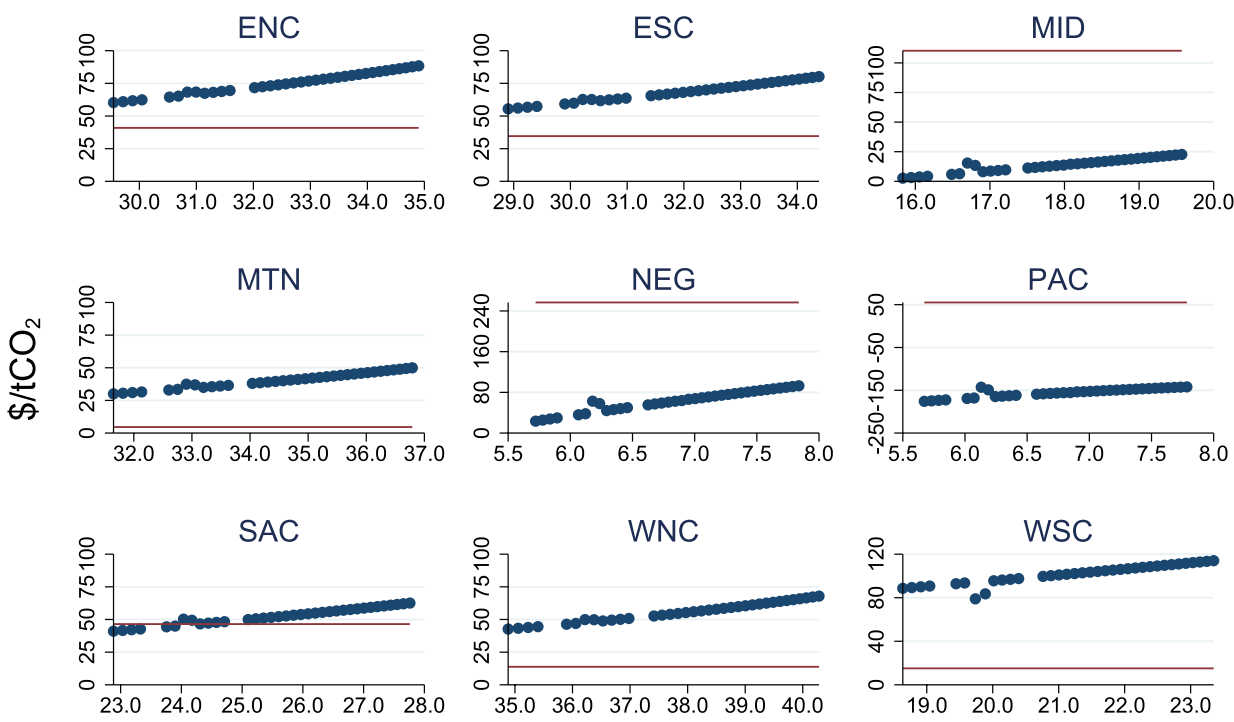

- Cost Co-benefit

Percent $\mathrm{CO}_{2}$ abatement

Figure 15. Marginal welfare cost and average co-benefit of $\mathrm{CO}_{2}$ abatement by region.

\section{Conclusion}

This analysis identified considerable regional heterogeneity in the costs and co-benefits of carbon taxes. Considering just a subset of climate policy co-benefits can substantially offset the policy's gross economic costs in the aggregate, however, the value of co-benefits is monetized but nonmonetary. That is, the co-benefits estimates reflect in 
large part individuals' willingness to pay for longer lifespans. Households in the lowest quintile or two may be materially impacted by even a $0.5 \%$ decline in their economic well-being in ways that higher-income households are not and for which longer life expectancies do not fully compensate.

Climate benefits aside, households in coastal regions, especially those in upper quintiles, are most likely to benefit from the climate policies considered here. The net benefits in coastal regions reflect a mix of higher co-benefits in east coast regions and lower marginal welfare costs of abatement on both coasts. At a national level, more than half of the marginal welfare costs of the policy are offset by the subset of co-benefits considered. The $\$ 27 / \mathrm{tCO}_{2}$ identified as an upper bound on the climate benefits required to justify the policy could be significantly reduced by considering other co-benefits.

Though not considered here, the extent of regional variation in costs and co-benefits suggests that a uniform national policy for revenue recycling is likely to be suboptimal. This analysis did not consider variation in co-benefits by income or on the margin of different abatement levels. Further research into how exposure, vulnerability, medical care efficacy, and willingness to pay for improved mortality and morbidity vary by income could reveal heterogeneity in co-benefits that alters our understanding of optimal climate policy design. Identifying the shape of the marginal co-benefit curve for climate policy will be especially important in considering deep decarbonization pathways, where the level of co-abatement will be much larger.

Welfare costs simulated by CGE models are particularly sensitive to the structure of factor markets. Model structures with less labor and capital mobility among sectors and regions of the economy will tend to produce higher welfare costs, all else equal. Model structures with more limited substitutability among factors of production, energy, and intermediate or consumption goods will also tend to produce higher welfare costs, all else equal. Future research that simulates a range of policy costs through monte-carlo analysis over model parameters or variations in factor market and commodity production structures can help characterize a distribution of welfare costs.

Parametrizing labor mobility within model simulations could mitigate welfare losses. Further research could make valuable contributions to the literature by parametrizing such mobility on the basis of empirical estimates of how key environmental and labor market conditions influence households' location decisions. For example, climate-change-induced migration could ease labor market shortages and surpluses to the extent adverse climate impacts are geographically concentrated within the US. Climate change could also alter stoichiometric and transport phenomena that determine how pollution emissions and ambient concentrations relate or the epidemiological relationships between ambient concentrations and health, which could significantly alter co-benefits estimates.

The future research identified above can improve the representation of key relationships within and among the costs, co-benefits, and climate impacts associated with different climate policy pathways in CGE and co-benefit models. Coupling these model refinements with region and sector-specific recycling schemes could offer 
valuable insights for optimal climate policy design. In all, furthering our understanding of the spatial and economic heterogeneity in economic costs, policy co-benefits, and ultimately climate benefits, will support policy makers in addressing the pressing need for climate policy without disproportionately impacting particular groups.

\section{References}

Burtraw, D, A Krupnick, K Palmer, A Paul, M Toman and C Bloyd (2003). Ancillary benefits of reduced air pollution in the US from moderate greenhouse gas mitigation policies in the electricity sector. Journal of Environmental Economics and Management, 45(3), 650-673.

Consumer Expenditures and Income (2016). Technical Report. Bureau of Labor Statistics, Washington, D.C.

Current Population Survey (2011). Technical Report. U.S. Department of Commerce, Census Bureau, Washington, D.C.

Fann, N, CM Fulcher and BJ Hubbell (2009). The influence of location, source, and emission type in estimates of the human health benefits of reducing a ton of air pollution. Air Quality, Atmosphere \& Health, 2(3), 169-176.

Groosman, B and NZ Muller (2011). The ancillary benefits from climate policy in the United States. Environmental Resource Economics, 50, 585-603.

Holland, SP (2010). Spillovers from climate policy.

IMPLAN (2013). State-Level U.S. Data for 2012. Huntersville, NC.

Internal Revenue Service (2014). County Data.

Jaramillo, P and NZ Muller (2016). Air pollution emissions and damages from energy production in the U.S.: 2002-2011. Energy Policy, 90, 202-211.

Macaluso, N, S Tuladhar, J Woollacott, JR McFarland, J Creason and J Cole (2018). The impact of carbon taxation and revenue recycling on U.S. industries. Climate Change Economics, 9(1), 1840005.

Morris, J, S Paltsev and J Reilly (2012). Marginal abatement costs and marginal welfare costs for greenhouse gas emissions reductions: Results from the EPPA model. Environmental Modeling \& Assessment, 17(4), 325-336.

Muller, NZ and R Mendelsohn (2007). Measuring the damages of air pollution in the United States. Journal of Environmental Economics and Management, 54, 1-14.

Nemet, GF, T Holloway and P Meier (2010). Implications of incorporating airquality cobenefits into climate change policymaking. Environmental Research Letters, 5(1), 014007.

Pizer, WA and R Kopp (2003). Calculating the Costs of Environmental Regulation.

Pizer, WA and R Kopp (2005). Chapter 25 Calculating the Costs of Environmental Regulation. In K-G Mäler and JRB T-H of EE Vincent (Eds.), Economywide and International Environmental Issues (Vol. 3, pp. 1307-1351). Elsevier.

Ross, MT (2009). Documentation of the Applied Dynamic Analysis of the Global Economy (ADAGE) Model.

Urban Institute and Brookings Institution Tax Policy Center (2017). Household income quintiles. Website, visited August, 2017: http://www.taxpolicycenter.org/statistics/household-income-quintiles

U.S. Environmental Protection Agency (2015a). Regulatory Impact Analysis for the Clean Power Plan Final Rule. Technical Report, U.S. Environmental Protection Agency, Research Triangle Park, NC. 


\section{J. Woollacott}

U.S. Environmental Protection Agency (2015b). User's manual for the Co-Benefits Risk Assessment (COBRA) Screening Model. Technical Report June, U.S. Environmental Protection Agency, Washington, D.C.

Wind Vision (2015). A new era for wind power in the United States. Technical Report. U.S. Department of Energy, Washington, D.C. 